\title{
Postoperative Radiotherapy for Squamous Cell Carcinoma of the Head and Neck
}

\author{
William M. Mendenhall, MD; Russell W. Hinerman, MD; Robert J. Amdur, MD; Robert S. Malyapa, MD, PhD; \\ Christopher D. Lansford, MD; John W. Werning, MD; and Douglas B. Villaret, MD
}

\begin{abstract}
This review discusses the role of postoperative radiotherapy (RT) for patients with squamous cell carcinoma of the head and neck. Patients with unfavorable pathologic features have a high-risk of local-regional recurrence and a decreased likelihood of survival after surgery alone. Postoperative RT reduces the risk of local-regional failure and probably improves survival. Patients who are at high risk for recurrence may benefit from more aggressive altered fractionation schedules to decrease the overall time from surgery to the completion of RT. Adjuvant cisplatin-based chemotherapy also appears to improve the probability of cure in high-risk patients.
\end{abstract}

Keywords: Head and neck; Radiotherapy; Squamous cell carcinoma

$\mathrm{T}$ he two main treatment modalities for patients with squamous cell carcinoma of the head and neck are surgery and radiotherapy (RT). Patients with stage I and II disease, as defined by the American Joint Committee on Cancer (AJCC), are optimally treated with one modality. ${ }^{1}$ Unfortunately, a substantial proportion of patients present with stage III and IV disease and, although organ preservation treatment strategies using RT alone or with concomitant chemotherapy have proven to be successful for patients with favorable low volume malignancies, those with unfavorable cancer have a low chance of cure. ${ }^{2}$ Depending on primary site and location, patients with advanced stage III to IV lesions are optimally treated with surgery. The rationale for postoperative RT is that it is most likely to be effective against microscopic deposits of cancer cells which, if they remain after resection, would progress and lead to a local-regional recurrence (recurrence at the primary site and/or neck). ${ }^{3}$ Although many clinicians currently recommend postoperative RT, some have suggested that although it may reduce the likelihood of local-regional recurrence, this may be offset by an increased risk of distant metastases so that survival is unchanged. If there is no survival benefit, one could argue to withhold RT and treat only those patients who relapse above the clavicles. ${ }^{4}$
The aim of this paper is to review the pertinent literature and to address the role of postoperative RT in the management of patients with resected head and neck cancer. The discussion will be limited, for the most part, to patients who have undergone at least resection of all gross tumor (R0 or R1 resection). The bias of the authors is to treat patients who would best be treated surgically, but are judged to have incompletely resectable cancers, with preoperative RT followed by reevaluation for an anticipated operation. ${ }^{5}$

\section{Adverse Prognostic Factors After Surgery Alone}

Pathologic factors predictive for local-regional recurrence after surgery may be related to the primary tumor and/or metastatic cervical nodes. Important parameters include close $(<5 \mathrm{~mm})$ or positive margins, tumor extension through the lymph node capsule (extracapsular extension), invasion of the soft tissues of the neck, more than $5 \mathrm{~mm}$ subglottic invasion, two or more positive lymph nodes, perineural invasion and endothelial-lined space invasion. ${ }^{6-9}$

Some of these factors are more ominous than others. For example, early bone erosion of the mandible is not likely to have the same negative prognostic impact as positive margins or extracapsular extension. One also might argue that for subglottic extension, $1 \mathrm{~cm}$ or more should be the threshold rather than $5 \mathrm{~mm}$. Additionally, less well-defined factors 
include an initially positive margin that is again resected until negative margins are achieved and/or the surgeon's uneasiness regarding final, apparently tumor-free margins. High risk of occult tumor in an undissected, clinically negative (N0) neck is not an adequate reason to add postoperative RT unless there are additional indications for treatment; the high-risk neck should be electively dissected. ${ }^{10}$

Ang et al $^{11}$ reported a prospective trial of 213 patients who were likely to require postoperative RT after surgery for squamous cell carcinoma of the oral cavity, oropharynx and hypopharynx. Pathologic T stage was T3 to T4 in $61 \%$ of patients, and $58 \%$ had N2 to N3 neck disease. The majority of patients had stage III (48\%) or IV (38\%) cancers. After surgery, 31 (15\%) had no adverse pathologic factors and received no additional treatment. These patients had a 5-year local-regional control rate of $83 \%$. This finding suggests that a small subset of patients who originally present with advanced cancer but, after surgery, are found to have no adverse pathologic factors likely have an excellent prognosis with surgery alone.

In contrast, Huang et $\mathrm{al}^{12}$ reported 71 patients with positive margins and/or extracapsular extension who were treated with surgery alone. The 3-year local control rates were: positive margins, 41\%; extracapsular extension, 31\%; and both, $0 \%$. Olsen et $\mathrm{al}^{8}$ reported a series of 284 patients with pathologic stage N1 and N2 squamous cell carcinoma treated with surgery alone. The 5-year neck-recurrence-free survival rates were as follows: N1, 76\%; N2, 60\%; and overall, 69\%. Multivariate analysis revealed the following parameters to be significantly associated with increased risk of neck recurrence: 4 or more positive nodes $(P=0.005)$, invasion of vascular or lymphatic spaces $(P=0.003)$, invasion of the soft tissues $(P=0.008)$ and desmoplastic stromal pattern $(P=0.0001)$.

In summary, a variety of factors are associated with an increased risk of local-regional recurrence after surgery alone. Positive margins and extracapsular extension are the two most unfavorable parameters. Because the likelihood of salvage is low after a local-regional recurrence, factors that adversely impact the probability of disease control above the clavicles are also likely to have a negative influence on survival.

\section{Does Postoperative RT Improve Local-Regional Control and Survival?}

Although no randomized trials have addressed the efficacy of postoperative adjuvant RT in the treatment of head and neck cancer, a study performed at the Medical College of Virginia pertaining to this issue is available. Two groups of surgeons operated on patients with head and neck cancer, general surgical oncologists who employed surgery alone and reserved RT for treatment of recurrent disease, and otolaryngologists who routinely sent patients with locally advanced disease for postoperative RT. ${ }^{12}$ Of the 441 patients treated surgically between 1982 and 1988, 125 had extracapsular extension and/or positive margins: 71 were treated with surgery alone and 54 received postoperative RT. Local control rates at 3 years after surgery alone compared with surgery and RT were as follows: extracapsular extension, $31 \%$ and $66 \%(P=0.03)$, respectively; positive margins, $41 \%$ and 49\% $(P=0.04)$, respectively; and extracapsular extension and positive margins, $0 \%$ and $68 \%(P=0.001)$, respectively. A multivariate analysis of local control was performed evaluating the impact of T stage, $\mathrm{N}$ stage, use of postoperative RT, the number of positive nodes, the number of nodes with extracapsular extension, primary site, microscopic and macroscopic extracapsular extension, and margin status. The use of postoperative RT $(P=0.0001)$, macroscopic extracapsular extension $(P=0.0001)$ and margin status $(P=0.09)$ significantly impacted local control. Disease-free survival at 3 years was $25 \%$ after surgery alone and $45 \%$ after surgery and postoperative RT $(P=0.0001)$. Cause-specific survival rates at 3 years were $41 \%$ for surgery alone and $72 \%$ for surgery and postoperative RT $(P=0.0003)$. Multivariate analysis of cause-specific survival showed that postoperative RT $(P=0.0001)$ and the number of nodes with extracapsular extension $(P=0.0001)$ significantly influenced this endpoint.

In another series, Lundahl et $\mathrm{al}^{13}$ reported on 95 patients with node-positive squamous cell carcinoma who were treated with surgery (that included a neck dissection) followed by postoperative RT. A matched-pair analysis was performed utilizing a series of patients treated with surgery alone; 56 matched pairs of patients were identified. The results showed that the rates of recurrence in the dissected neck $(R R=5.82$; $P=0.0002)$, recurrence in either side of the neck $(\mathrm{RR}=2.21$; $P=0.0052)$, and death from any cause $(\mathrm{RR}=1.67 ; P=0.0182)$ were significantly higher for patients treated with surgery alone.

Thus, it would appear that for patients who are at high-risk for local-regional failure following surgery, postoperative RT may significantly improve both disease control above the clavicles and survival.

\section{Postoperative RT Technique}

At the University of Florida, patients are treated with 4 to 6 MV X-rays at 2.0 Gy per fraction, one fraction per day, five days per week, in a continuous course. The total dose depends on the likelihood and density of occult residual disease and usually varies from 60 to $66 \mathrm{~Gy}$. For patients who have undergone a partial laryngectomy, the dose is reduced to 55.8 Gy at 1.8 Gy per fraction because of an increased risk of complications. ${ }^{14}$ The primary site and upper neck are irradiated with parallel opposed fields and the low neck is irradiated with an en face anterior field with the dose specified at the maximum depth. The inferior border of the lateral fields is placed at the top of the stoma for patients who have undergone a total laryngectomy (figure 1). Although no midline block is used in the low neck field, the dose to the spinal cord is low because the central axis is placed at the superior border so that the beam is nondivergent, and because the inferior border of the lateral fields slopes superiorly as it 

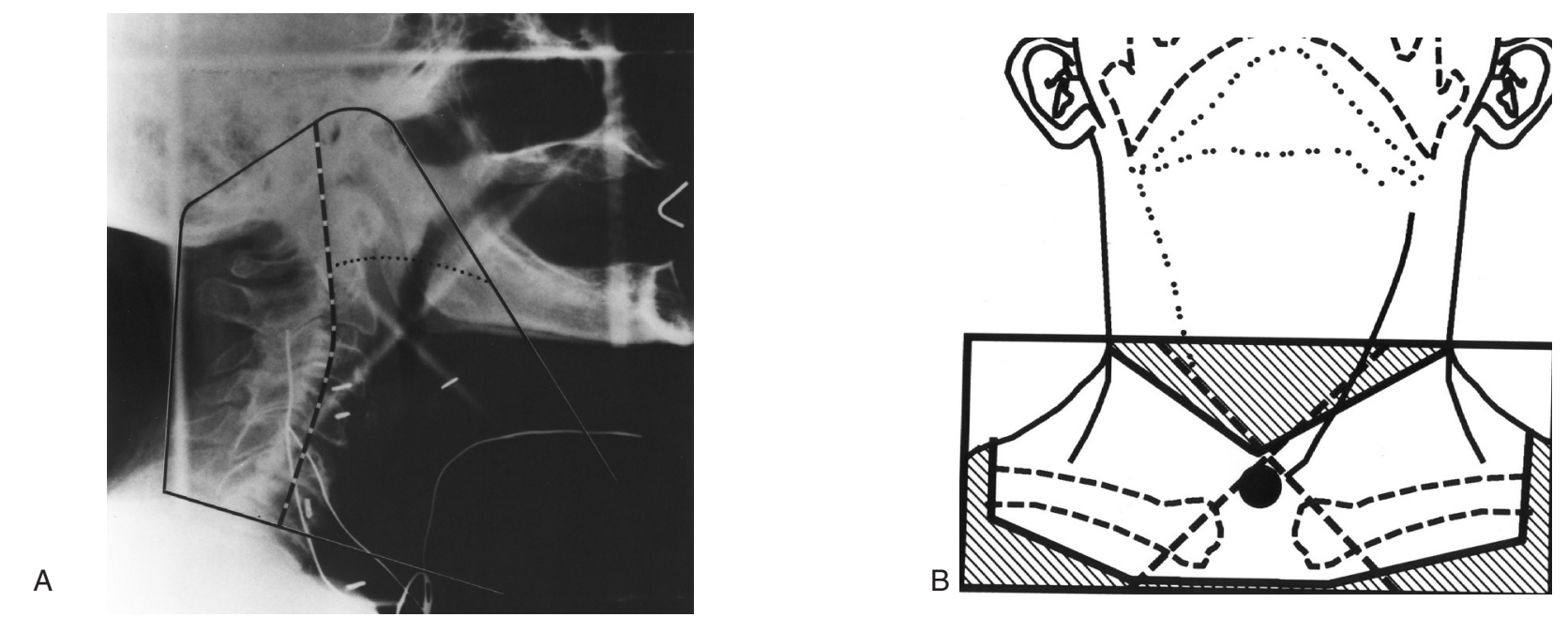

Figure 1. Fields for postoperative irradiation of a patient with advanced cancer of the laryngopharynx. (A) Typical simulation film. The initial "off cord" reduction (50 Gy) is indicated by the dashed line and the final reduction (60 Gy) by the dotted line. Wires mark the surgical scars and stoma. Slanting line used on lower border reduces the length of spinal cord treated by the primary field, allows better caudal coverage of the mucosal surfaces while simultaneously bypassing the shoulders, and facilitates matching the low neck field. (B) Schematic diagram of low neck field. The rectangle (solid line) represents the light field. The dashed lines denote the central axis. The shaded areas represent the blocked portions of the field. The superior border of the neck field is the inferior border of the primary field. The actual line is treated only in the primary field. The upper border of the low neck field assumes a $V$ shape. In the midline of the patient, the apex of the $\mathrm{V}$ generally is at or close to the central axis, so that the portion of the low neck portal that treats the spinal cord is nondivergent in its upper portion and diverges away from the primary fields in its lower portion. At the junction of the three fields, a short $(2-3 \mathrm{~cm})$ segment of spinal cord remains untreated by any of the three fields (Reprinted with permission of Elsevier from Amdur RJ et al. Postoperative irradiation for squamous cell carcinoma of the head and neck: an analysis of treatment results and complications. Int $J$ Radiat Oncol Biol Phys 1989;16:25-36. Copyright 1989 Elsevier. All rights reserved).

proceeds posteriorly. The lower border of the lateral fields is placed at approximately the thyroid notch for patients with malignancies of the oral cavity (figure 2). A tapered midline block is placed in the anterior en face low neck field with the inferior border of the block at approximately the bottom of the cricoid cartilage. Relatively recent technical advances in the RT of head and neck cancer patients include the use of three-dimensional computed tomography (CT) treatment planning and intensity modulated radiation therapy (IMRT). The latter technique may be used to reduce the dose delivered to one or more of the major salivary glands, thus reducing the likelihood of long-term xerostomia. ${ }^{15}$

The addition of postoperative RT does not adversely influence the likelihood of flap viability in patients who undergo a reconstructive procedure so long as they are well healed prior to initiating RT. ${ }^{16}$ Wang et al ${ }^{16}$ analyzed the success and healing rates of reconstructive flaps in 74 patients who received postoperative RT and observed them to be $99 \%$ and $95 \%$, respectively. Similarly, postoperative RT does not diminish the probability of a successful outcome in patients who undergo titanium plate mandibular reconstruction. ${ }^{17}$ Wang and colleagues ${ }^{17}$ analyzed the complication rates in 66 patients treated with surgery alone (32 patients) or surgery and postoperative RT (34 patients) and found that the probability of a major complication ( $19 \%$ vs. $29 \%, P=0.312$ ) and the requirement for plate removal $(13 \%$ vs. $21 \%$, $P=0.378$ ) was not significantly different.

\section{Adverse Prognostic Factors After Surgery and Postoperative RT}

Vikram ${ }^{18}$ was among the first to report a decreased likelihood of cure secondary to delay in initiation of postoperative RT in a series of 21 patients treated at the Memorial Sloan-Kettering Cancer Center. Schiff et al ${ }^{19}$ updated this experience in a series of 111 patients treated with surgery and postoperative RT. Patients who received $<60$ Gy had an increased risk of failure if the interval between surgery and RT exceeded 6 weeks $(P<0.05)$. There was no adverse impact of delay over 6 weeks if the RT dose was $>60 \mathrm{~Gy}$. In contrast, Bastit et al ${ }^{20}$ recently reported a series of 2052 patients treated with surgery and postoperative RT for carcinoma of the oropharynx and hypopharynx at the Centre Henri Becquerel. They found that the interval between the two modalities had no significant impact on local-regional control or survival.

Altered fractionation has been used to reduce overall treatment time and improve the likelihood of cure for patients treated with RT alone. ${ }^{21}$ The overall treatment time is influenced by both the interval between surgery and postoperative RT, as well as the dose-fractionation schedule. It can be shortened by treating on weekends or by using two or more fractions per day for all or part of the irradiation course. Hinerman et al ${ }^{22}$ reported on 226 patients treated with surgery and continuous-course RT at the University of Florida for squamous cell carcinoma of the oral cavity. Patients were considered to be in a favorable category if they had $<3$ indications for postoperative RT and unfavorable if there were 3 or more indications. Patients in the unfavorable category 
tended to have a higher risk of local-regional failure if the interval between surgery and RT exceeded 51 days or if the overall time from the date of the operation to completion of RT was $>101$ days. In a similar study, Rosenthal et al23 reported a series of 208 patients treated with surgery and once daily postoperative RT at the University of Pennsylvania between 1992 and 1997. Patients were stratified into intermediate- and high-risk groups and overall treatment time was defined as "short" (100 days or less) and "long" (more than 100 days). Multivariate analysis revealed that both risk group and overall treatment time significantly influenced local-regional control ( $P=0.017$ and $P=0.022$; respectively) and overall survival ( $P<0.001$ and $P=0.035$, respectively). In a recent study, Ang et al ${ }^{11}$ reported a prospective trial of 213 patients who were treated surgically and stratified as follows: low risk, no adverse pathologic factors; intermediate risk, one adverse pathologic factor other than extracapsular extension; and high risk, extracapsular extension and/or two or more adverse pathologic factors. Low-risk patients received no further treatment, intermediate-risk patients received 57.6 Gy in 6.5 weeks, and high-risk patients were randomized to receive conventionally fractionated RT with 63 Gy in 7 weeks, or 63 Gy in 5 weeks with altered fractionation. A prolonged interval between surgery and the initiation of conventionally fractionated RT was associated with decreased local-regional control $(P=0.02)$ and survival $(P=0.01)$ for high-risk patients. In contrast, high-risk patients treated with accelerated fractionation had no difference in local-regional control $(P=0.36)$ or survival $(P=0.50)$ as a function of the interval between the two modalities. Overall treatment time significantly influenced local-regional control $(P=0.005)$ and survival $(P=0.03)$ for high-risk patients. Taken together, these findings suggest that high-risk patients who experience a significant delay ( $>6$ weeks) between surgery and postoperative irradiation may benefit from altered fractionation to reduce the overall treatment time and offset, in part, the adverse impact of accelerated tumor repopulation that likely occurs. Although altered fractionation is usually associated with increased acute toxicity, late toxicity is similar to that observed after conventional fractionation. ${ }^{21}$

Another treatment-related issue that may influence the likelihood of cure is beam energy. In the past, patients were often treated with cobalt 60 , which delivers a high proportion of the dose to subcutaneous tissues. Currently, the lowest energy beam in most departments is $6 \mathrm{MV} \mathrm{X}$-rays, and there is a possibility that tumor in the subcutaneous tissues may be underdosed. This is of particular concern in the low neck where a single en face field is used, but is less of an issue in the upper neck where parallel, opposed portals are employed and the exit dose from the contralateral side contributes to the dose in the ipsilateral subcutaneous tissues. Fortin et $\mathrm{al}^{24}$ reported a study of 471 patients treated with postoperative cobalt 60 (212 patients) or $6 \mathrm{MV}$ X-rays (259 patients) at the L' Hôtel Dieu de Québec between 1989 and 1997. Whereas the overall local control rate was better for patients treated with 6 MV X-rays, the neck control rate tended to be improved for high-risk patients (extracapsular extension, more than 2 positive nodes and/or T4 primary) treated with cobalt 60 $(P=0.09)$. Multivariate analysis revealed that high-risk patients
A

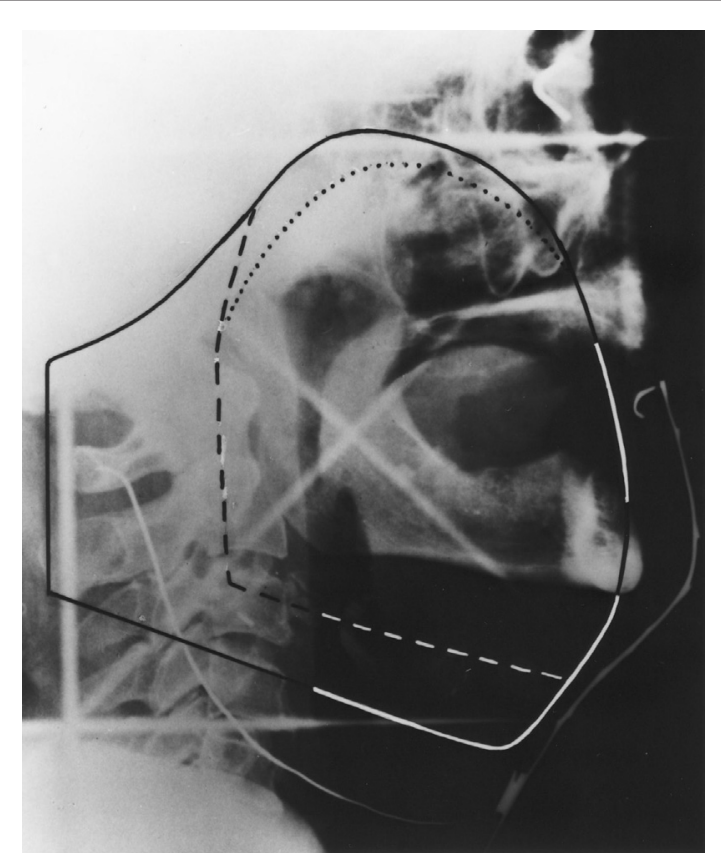

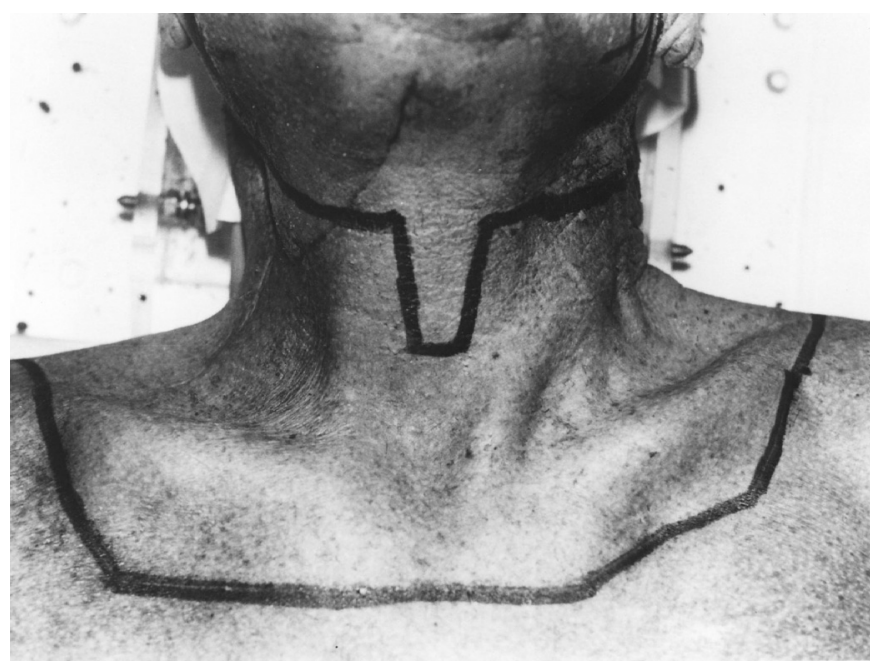

B

Figure 2. Typical portal after a hemimandibulectomy, partial maxillectomy and radical neck dissection for a pathologic T4 N0 retromolar trigone lesion. (A) Field reductions were made at 45 Gy (dashed line) and 60 Gy (dotted line). (B) The low neck received 50 Gy given dose (at Dmax) in 25 fractions. The larynx and a segment of the spinal cord were shielded by a tapered midline block (Reprinted with permission of Elsevier from Amdur RJ et al. Postoperative irradiation for squamous cell carcinoma of the head and neck: an analysis of treatment results and complications. Int J Radiat Oncol Biol Phys 1989;16:25-36. Copyright 1989 Elsevier. All rights reserved). 
treated with cobalt 60 had a significantly higher likelihood of neck control $(P=0.03)$. Aref et $\mathrm{al}^{25}$ recently reported a secondary analysis of Intergroup Study 003426 in which 392 patients with advanced squamous cell carcinoma of the oral cavity, oropharynx, hypopharynx and larynx underwent surgery and were randomized to receive postoperative RT alone or combined with three cycles of induction cisplatin and fluorouracil. Patients were stratified into high-risk $(<5$ $\mathrm{mm}$ margins, extracapsular extension and/or carcinoma in situ at the margins) and low-risk (all others) groups. Patients were irradiated using cobalt 60 (157 patients), 4 MV X-rays (140 patients), or $6 \mathrm{MV}$ X-rays (95 patients). Beam energy had no significant impact on acute or late toxicity. There was also no significant difference $(P=0.61)$ in local-regional control: cobalt 60 (75\%), $4 \mathrm{MV}$ X-rays (79\%), and $6 \mathrm{MV}$ X-rays $(80 \%)$. Thus, it appears that most patients may be adequately irradiated with $6 \mathrm{MV}$ X-rays.

In addition to treatment-related parameters, a variety of clinical and pathologic factors have been correlated with prognosis after surgery and postoperative RT. Hinerman et $\mathrm{a}^{22}$ analyzed local-regional control in 226 patients treated with surgery and postoperative RT for squamous cell carcinoma of the oral cavity. Multivariate analysis revealed that advanced T-stage, extracapsular extension, positive margins, perineural invasion and vascular invasion significantly increased the risk of a local-regional failure (table 1). Additionally, extracapsular extension, perineural invasion and advanced T-stage had an adverse impact on the likelihood of cause-specific survival (table 2). Peters et al ${ }^{7}$ reported a prospective trial including 240 patients treated with surgery and postoperative RT at the M.D. Anderson Cancer Center. Clusters of two or more of the following factors were associated with an increased risk of recurrence: oral cavity primary site, close or positive mucosal margins, nerve invasion, two or more positive nodes, largest node more than $3 \mathrm{~cm}$, RT treatment delay more than 6 weeks postoperatively and Zubrod performance status $\geq 2$. Analysis of variables predictive of local-regional control revealed that the only independent variable of note was extracapsular extension. Pfreundner et al ${ }^{27}$ reported on 257 patients treated with surgery and postoperative RT at the University of Wuerzburg between 1987 and 1997. Patients were treated with once-daily 2 Gy per fraction, 5 days per week to a median dose of 56 Gy. Resection margins were defined as negative ( $>3 \mathrm{~mm}, 64$ patients), close ( $<3 \mathrm{~mm}, 66$ patients), R1 (microscopically positive, 101 patients) and R2 (gross residual, 26 patients). In patients with close margins or residual disease, the tumor bed was boosted to a median dose of 66 Gy. Five-year local-regional control and survival rates were as follows: negative margins, $100 \%$ and $67 \%$, respectively; close margins, $92 \%$ and $59 \%$, respectively; R1 resection, $87 \%$ and $26 \%$, respectively; and $\mathrm{R} 2$ resection, $69 \%$ and $27 \%$, respectively. Multivariate analysis of local-regional control revealed that only resection margins $(P=0.00031)$ and high RT dose $(P=0.0046)$ were significantly associated with this endpoint. $\mathrm{T}$ stage $(P=0.144), \mathrm{N}$ stage $(P=0.166)$,
Table 1. Multivariate analysis of pathologic variables affecting local-regional control after surgery and postoperative radiotherapy.

\begin{tabular}{ll}
\hline Risk factor & $\boldsymbol{P}$-value \\
\hline T stage & 0.0002 \\
ECE & 0.0037 \\
Margins & 0.0102 \\
Perineural invasion & 0.0103 \\
Vascular invasion & 0.0258 \\
N stage & 0.1108 \\
Overall stage & 0.1541 \\
Bone invasion & 0.3045 \\
Differentiation & 0.5916 \\
\hline
\end{tabular}

ECE, extracapsular nodal spread.

Reprinted with permission of John Wiley \& Sons from Hinerman RW et al. Postoperative irradiation for squamous cell carcinoma of the oral cavity: 35-year experience. Head Neck 2004;26:984-994. Copyright 2004 John Wiley \& Sons. All rights reserved.

extracapsular extension $(P=0.120)$, lymphangiosis carcinomatosa $(P=0.525)$ and adjuvant chemotherapy did not significantly influence local-regional control. Multivariate analysis of survival revealed that total dose $(P<0.00000)$, resection margins $(P=0.000015), \mathrm{T}$ stage $(P=0.0057)$ and $\mathrm{N}$ stage $(P=0.024)$ significantly influenced this endpoint. Survival was marginally impacted by the presence of extracapsular extension $(P=0.055)$ and lymphangiosis carcinomatosa $(P=0.066)$.

In summary, patients with unfavorable factors, such as positive margins and extracapsular extension, have an increased risk of local-regional failure after surgery and postoperative RT. Extended overall treatment time may be associated with an increased risk of recurrence, particularly for high-risk patients. Altered fractionation may be used to

Table 2. Multivariate analysis of pathologic variables affecting cause-specific survival after surgery and postoperative radiotherapy.

\begin{tabular}{ll}
\hline Risk factor & $\boldsymbol{P}$-value \\
\hline ECE & 0.0001 \\
Perineural invasion & 0.0205 \\
T stage & 0.0612 \\
Vascular invasion & 0.2040 \\
Differentiation & 0.2599 \\
Bone invasion & 0.5086 \\
Overall stage & 0.4521 \\
N stage & 0.6982 \\
Margins & 0.8837
\end{tabular}

ECE, extracapsular nodal spread.

Reprinted with permission of John Wiley \& Sons from Hinerman RW et al. Postoperative irradiation for squamous cell carcinoma of the oral cavity: 35-year experience. Head Neck 2004;26:984-994. Copyright 2004 John Wiley \& Sons. All rights reserved. 
Table 3. Five year local-regional control rates versus resection margins and radiotherapy. ${ }^{27}$

\begin{tabular}{lcccc}
\hline Margins & $\begin{array}{c}\text { No. } \\
\text { patients }\end{array}$ & $\begin{array}{c}\text { Radiotherapy } \\
\text { dose }\end{array}$ & $\begin{array}{c}\mathbf{5} \text { year local- } \\
\text { regional control }\end{array}$ & $\boldsymbol{P}$-value \\
\hline Close $(<3 \mathrm{~mm})$ & 66 & $\leq 66 \mathrm{~Gy}$ & $62 \%$ & 0.07 \\
& & $>66 \mathrm{~Gy}$ & $80 \%$ & 0.0002 \\
Gross total excision with positive margins & 101 & $\leq 68 \mathrm{~Gy}$ & $28 \%$ & 0.15 \\
Gross residual disease & & $>68 \mathrm{~Gy}$ & $50 \%$ & $84 \%$ \\
\end{tabular}

offset the adverse impact of high-risk factors and/or a prolonged interval between surgery and postoperative RT.

\section{Time to Recurrence and Salvage After Local-Regional Relapse}

Hinerman et al ${ }^{22}$ observed a local-regional recurrence in 55 of 226 patients $(24 \%)$. The median time to recurrence was 5.4 months and $91 \%$ were detected within 2 years.

Fifty-eight (24\%) of 240 patients treated with surgery and postoperative RT at the M.D. Anderson Hospital developed a local-regional recurrence. ${ }^{7}$ Thirty-six patients underwent salvage therapy with surgery alone or combined with chemotherapy (11 patients), RT alone or combined with chemotherapy (3 patients) or chemotherapy alone (22 patients). Only 1 of 58 patients (2\%) was a "long term survivor" 22 months after salvage therapy. Thus, the probability of successful salvage is remote and treatment must be designed to maximize the chance of cure with the initial operation and adjuvant RT.

Prognostic Influence of Dose-Fractionation Parameters Zelefsky et $\mathrm{al}^{9}$ reported a study of 102 patients treated with surgery and postoperative RT at Memorial Sloan-Kettering Cancer Center for squamous cell carcinoma of the oral cavity and oropharynx. Margins were microscopically positive in 25 patients, close $(\leq 5 \mathrm{~mm})$ in 41 patients and negative in 36 patients. The median postoperative dose was $60 \mathrm{~Gy}$. Patients with close or positive margins and a non-oral-tongue primary site had a 7-year local control rate of $92 \%$ for doses of $60 \mathrm{~Gy}$ or more compared with $44 \%$ for those who received $<60$ Gy $(P=0.0007)$.

Pfreundner et $\mathrm{al}^{27}$ observed an improvement in the probability of local-regional control at 5 years when patients were stratified according to resection margins (table 3). Patients were treated once daily at 2 Gy per fraction. Multivariate analysis revealed that increasing dose was associated with increased local-regional control and survival. Peters et $\mathrm{al}^{7}$ reported on 240 patients who were included in a prospective study of surgery and postoperative RT. Patients were stratified into low- and high-risk groups based on clinical stage and pathologic parameters. Patients underwent resection of all gross tumor and were irradiated once daily at 1.8 Gy per fraction. Low-risk patients were initially randomized to receive either 52.2 to $54 \mathrm{~Gy}$, or $63 \mathrm{~Gy}$; the lower dose arm was increased to 57.6 after an interim analysis showed a higher risk of recurrence in patients who received 52.2 to $54 \mathrm{~Gy}$. High-risk patients were randomized to receive either 63 Gy or 68.4 Gy. Low-risk patients who received 54 Gy or less had a significantly higher local failure rate than those who received 57.6 Gy or more. No significant dose response was observed at doses more than 57.6 Gy except for patients with extracapsular extension. Such patients who received 63 Gy or more had a significantly higher control rate than those who received 57.6 Gy $(P=0.03)$. Doses more than 63 Gy did not seem to be beneficial.

The overall time from surgery to the completion of RT has been shown to be inversely related to prognosis for some subsets of high-risk patients. ${ }^{11,22,28}$ Therefore, it stands to reason that the overall time of the RT course might influence the effectiveness of the treatment. Amdur et a ${ }^{29}$ reported results of 161 patients treated once-daily with continuous (134 patients) or planned split-course (27 patients) postoperative RT. Patients treated with the planned split-course technique, which was routinely employed between 1970 and 1974, had a significantly worse outcome (table 4). Multivariate analysis revealed that splitcourse RT was associated with a significantly increased risk of local-regional relapse and death with cancer present. Patients treated with split-course RT had the same likelihood of acute and late complications as those treated with continuous-course RT. In another study, ${ }^{22} 226$ patients with 230 oral cavity tumors were treated with continuous-course either once-daily (149 patients) or twice-daily (69 patients) postoperative RT. Eight additional patients received a brachytherapy boost after external beam RT. ${ }^{22}$ Patients treated twice daily usually had close or positive margins and were irradiated at 1.2 Gy per fraction and tended to receive a somewhat higher dose over a shorter period of time. The 5 year local-regional control rates for patients with positive margins treated with twice-daily RT was $65 \%$ for those who received 74.4 Gy or more compared with $40 \%$ for those who received lower doses $(P=0.0477)$. Ang et $\mathrm{al}^{11}$ recently reported a prospective trial in which high-risk patients who had a significant delay between surgery and postoperative RT had an improved outcome with a more aggressive altered fractionation schedule compared with those irradiated once daily. 
Table 4. Five-year outcome for continuous-course versus planned split-course postoperative radiotherapy. ${ }^{29}$

\begin{tabular}{lccc}
\hline Parameter & Split course $(\boldsymbol{n = 2 7})$ & Continuous course $(\boldsymbol{n}=\mathbf{1 3 4})$ & $\boldsymbol{p}$-value \\
\hline Local-regional control & $44 \%$ & $80 \%$ & 0.002 \\
Survival & $15 \%$ & $33 \%$ & 0.005 \\
Cause specific survival & $37 \%$ & $57 \%$ & $<0.001$ \\
\hline
\end{tabular}

Therefore, it would appear that some subsets of high-risk patients may benefit from a more aggressive course of postoperative RT. Intensification of the treatment may be accomplished by increasing the total dose and reducing the overall treatment time. Achieving the latter may be done by treating on weekends or using an altered fractionation schedule.

\section{Adjuvant Chemotherapy and Future Directions}

Although postoperative RT is associated with an improved prognosis for patients with advanced head and neck cancer, a substantial proportion of high-risk patients relapse and have only a remote probability of survival.

Concomitant chemotherapy has been shown to be beneficial for patients with advanced stage III-IV disease treated with RT alone. ${ }^{30-35}$ Bachaud et al ${ }^{36}$ reported a prospective trial in which 83 patients with stage III-IV head and neck cancer with extracapsular extension underwent surgery and were then randomized to postoperative RT alone or combined RT and weekly cisplatin $(50 \mathrm{mg})$. Patients who received adjuvant cisplatin had improved local-regional control $(P=0.05)$, cause-specific survival $(P<0.05)$ and overall survival $(P<0.01)$. There was no difference in the rates of distant metastases or late complications. A recent multi-institution trial reported by Bernier and colleagues ${ }^{37}$ included 334 patients who were operated on for locally advanced squamous cell carcinoma of the oral cavity, oropharynx, larynx and hypopharynx, and were then randomized to postoperative RT alone or combined with concomitant cisplatin. Radiotherapy was given once daily in $2 \mathrm{~Gy}$ fractions up to a total dose of 66 Gy. Cisplatin was delivered $100 \mathrm{mg} / \mathrm{m}^{2}$ on days 1,22 and 43 of RT. At a median 60 months of follow-up, patients treated with adjuvant chemotherapy had significantly improved 5 -year progression-free survival rates $(47 \%$ vs. $26 \%, P=0.04)$ and 5 -year overall survival rates $(53 \%$ vs. $40 \%, P=0.02)$. Similarly, local-regional control $(P=0.007)$ was significantly higher in those who were randomized to receive cisplatin. There was no difference in late complications between the two arms. Cooper et al ${ }^{38}$ recently conducted a prospective multi-institution trial in which 459 patients were randomized to receive postoperative RT alone (231 patients) or with concomitant cisplatin (228 patients). The addition of adjuvant chemotherapy was associated with a significant improvement in local-regional control and disease-free survival. However, overall survival was similar and acute toxicity was more pronounced in those who received chemotherapy. ${ }^{38}$
Ongoing trials continue to define the role of adjuvant chemotherapy combined with postoperative RT. The addition of an epidermal growth factor inhibitor, Cetuximab, has been shown to improve outcome when combined with definitive RT compared with RT alone. ${ }^{39}$ It is likely that a similar strategy would be effective when combined with adjuvant RT. In addition, the development of new experimental therapies used as adjuvant to RT, particularly those targeted to the tumor vasculature, ${ }^{40}$ may provide an increased likelihood of cure for patients with advanced head and neck cancer.

\section{References}

1. American Joint Committee on Cancer. AJCC Cancer Staging Manual. $5^{\text {th }}$ ed. Philadelphia, PA: Lippincott -Raven, 1997. 21-58.

2. Mendenhall WM, Morris CG, Amdur RJ, Hinerman RW, Mancuso AA. Parameters that predict local control after definitive radiotherapy for squamous cell carcinoma of the head and neck. Head Neck 2003;25:535-542.

3. MacComb WS, Fletcher GH. Planned combination of surgery and radiation in treatment of advanced primary head and neck cancers. Am J Roentgenol Radium Ther Nucl Med 1957;77:397-414.

4. DeSanto LW, Beahrs OH, Holt JJ, O'Fallon WM. Neck dissection and combined therapy. Study of effectiveness. Arch Otolaryngol 1985;111:366-370.

5. Fletcher GH. Basic principles of the combination of irradiation and surgery. Int J Radiat Oncol Biol Phys 1979;5:2091-2096.

6. Amdur RJ, Parsons JT, Mendenhall WM, Million RR, Stringer SP, Cassisi NJ. Postoperative irradiation for squamous cell carcinoma of the head and neck: an analysis of treatment results and complications. Int J Radiat Oncol Biol Phys 1989;16:25-36.

7. Peters LJ, Goepfert H, Ang KK, Byers RM, Maor MH, Guillamondegui O, Morrison WH, Weber RS, Garden AS, Frankenthaler RA, Oswald MJ, Brown BW. Evaluation of the dose for postoperative radiation therapy of head and neck cancer: First report of a prospective randomized trial. Int J Radiat Oncol Biol Phys 1993;26:3-11.

8. Olsen KD, Caruso M, Foote RL, Stanley RJ, Lewis JE, Buskirk SJ, Frassica DA, DeSanto LW, O'Fallon WM, Hoverman VR. Primary head and neck cancer. Histopathologic predictors of recurrence after neck dissection in patients with lymph node involvement. Arch Otolaryngol Head Neck Surg 1994;120:1370-1374.

9. Zelefsky MJ, Harrison LB, Fass DE, Armstrong JG, Shah JP, Strong EW. Postoperative radiation therapy for squamous cell carcinomas of the oral cavity and oropharynx: impact of therapy on patients with positive surgical margins. Int $\mathrm{J}$ Radiat Oncol Biol Phys 1993;25:17-21.

10. Mendenhall WM, Million RR. Elective neck irradiation for squamous cell carcinoma of the head and neck: analysis of time-dose factors and causes of failure. Int J Radiat Oncol Biol Phys 1986;12:741-746. 
11. Ang KK, Trotti A, Brown BW, Garden AS, Foote RL, Morrison WH, Geara FB, Klotch DW, Goepfert H, Peters LJ.

Randomized trial addressing risk features and time factors of surgery plus radiotherapy in advanced head-and-neck cancer. Int J Radiat Oncol Biol Phys 2001;51:571-578.

12. Huang DT, Johnson CR, Schmidt-Ullrich R, Grimes M. Postoperative radiotherapy in head and neck carcinoma with extracapsular lymph node extension and/or positive resection margins: a comparative study. Int J Radiat Oncol Biol Phys 1992;23:737-742.

13. Lundahl RE, Foote RL, Bonner JA, Suman VJ, Lewis JE, Kasperbauer JL, McCaffrey TV, Olsen KD. Combined neck dissection and postoperative radiation therapy in the management of the high-risk neck: a matched-pair analysis. Int J Radiat Oncol Biol Phys 1998;40:529-534.

14. Lee NK, Goepfert H, Wendt CD. Supraglottic laryngectomy for intermediate-stage cancer: U.T. M.D. Anderson Cancer Center experience with combined therapy. Laryngoscope 1990;100:831-836.

15. Pacholke HD, Amdur RJ, Morris CG, Li JG, Dempsey JF, Hinerman RW, Mendenhall WM. Late xerostomia after intensity-modulated radiation therapy versus conventional radiotherapy. Am J Clin Oncol 2005;28:351-358.

16. Wang Z, Qiu W, Mendenhall WM. Influence of radiation therapy on reconstructive flaps after radical resection of head and neck cancer. Int J Oral Maxillofac Surg 2003;32:35-38.

17. Wang ZH, Zhang ZY, Mendenhall WM. Postoperative radiotherapy after titanium plate mandibular reconstruction for oral cavity cancer. Am J Clin Oncol 2005;28:460-463.

18. Vikram B. Importance of the time interval between surgery and postoperative radiation therapy in the combined management of head \& neck cancer. Int J Radiat Oncol Biol Phys 1979;5:1837-1840.

19. Schiff PB, Harrison LB, Strong EW, Fass DE, Shah JP, Spiro R, Sessions R, Gerold F, Vikram B, Fuks ZY. Impact of the time interval between surgery and postoperative radiation therapy on locoregional control in advanced head and neck cancer. J Surg Oncol 1990;43:203-208.

20. Bastit L, Blot E, Debourdeau P, Menard J, Bastit P, Le Fur R. Influence of the delay of adjuvant postoperative radiation therapy on relapse and survival in oropharyngeal and hypopharyngeal cancers. Int J Radiat Oncol Biol Phys 2001;49:139-146.

21. Mendenhall WM, Riggs CE, Amdur RJ, Hinerman RW, Villaret DB. Altered fractionation and/or adjuvant chemotherapy in definitive irradiation of squamous cell carcinoma of the head and neck. Laryngoscope 2003;113:546-551.

22. Hinerman RW, Mendenhall WM, Morris CG, Amdur RJ, Werning JW, Villaret DB. Postoperative irradiation for squamous cell carcinoma of the oral cavity: 35-year experience. Head Neck 2004;26:984-994.

23. Rosenthal DI, Liu L, Lee JH, Vapiwala N, Chalian AA, Weinstein GS, Chilian I, Weber RS, Machtay M. Importance of the treatment package time in surgery and postoperative radiation therapy for squamous carcinoma of the head and neck. Head Neck 2002;24:115-126.

24. Fortin A, Allard J, Albert M, Roy J. Outcome of patients treated with cobalt and $6 \mathrm{MV}$ in head and neck cancers. Head Neck 2001;23:181-188.

25. Aref A, Berkey BA, Schwade JG, Ensley J, Schuller DE, Haselow RE, Ervin TJ, Laramore GE. The influence of beam energy on the outcome of postoperative radiotherapy in head and neck cancer patients: secondary analysis of RTOG 85-03. Int J Radiat Oncol Biol Phys 2000;47:389-394.
26. Laramore GE, Scott CB, Al-Sarraf M, Haselow RE, Ervin TJ, Wheeler R, Jacobs JR, Schuller DE, Gahbauer RA, Schwade JG, Campbell BH. Adjuvant chemotherapy for resectable squamous cell carcinomas of the head and neck: report on Intergroup Study 0034. Int J Radiat Oncol Biol Phys 1992;23:705-713.

27. Pfreundner L, Willner J, Marx A, Hoppe F, Beckmann G, Flentje M. The influence of the radicality of resection and dose of postoperative radiation therapy on local control and survival in carcinomas of the upper aerodigestive tract. Int J Radiat Oncol Biol Phys 2000;47:1287-1297.

28. Parsons JT, Mendenhall WM, Stringer SP, Cassisi NJ, Million RR. An analysis of factors influencing the outcome of postoperative irradiation for squamous cell carcinoma of the oral cavity. Int J Radiat Oncol Biol Phys 1997;39:137-148.

29. Amdur RJ, Parsons JT, Mendenhall WM, Million RR, Cassisi NJ. Split-course versus continuous-course irradiation in the postoperative setting for squamous cell carcinoma of the head and neck. Int J Radiat Oncol Biol Phys 1989;17:279-285.

30. Pignon JP, Bourhis J, Domenge C, Designe L. Chemotherapy added to locoregional treatment for head and neck squamous-cell carcinoma: three meta-analyses of updated individual data. MACH-NC Collaborative Group. Meta-Analysis of Chemotherapy on Head and Neck Cancer. Lancet 2000;355:949-955.

31. Jeremic B, Shibamoto Y, Milicic B, Nikolic N, Dagovic A, Aleksandrovic J, Vaskovic Z, Tadic L. Hyperfractionated radiation therapy with or without concurrent low-dose daily cisplatin in locally advanced squamous cell carcinoma of the head and neck: a prospective randomized trial. J Clin Oncol 2000;18:1458-1464.

32. Brizel DM, Albers ME, Fisher SR, Scher RL, Richtsmeier WJ, Hars V, George SL, Huang AT, Prosnitz LR.

Hyperfractionated irradiation with or without concurrent chemotherapy for locally advanced head and neck cancer. $\mathrm{N}$ Engl J Med 1998;338:1798-1804.

33. Calais G, Alfonsi M, Bardet E, Sire C, Germain T, Bergerot P, Rhein B, Tortochaux J, Oudinot P, Bertrand P. Randomized trial of radiation therapy versus concomitant chemotherapy and radiation therapy for advanced-stage oropharynx carcinoma. J Natl Cancer Inst 1999;91:2081-2086.

34. Adelstein DJ, Lavertu P, Saxton JP, Secic M, Wood BG, Wanamaker JR, Eliachar I, Strome M, Larto MA. Mature results of a phase III randomized trial comparing concurrent chemoradiotherapy with radiation therapy alone in patients with stage III and IV squamous cell carcinoma of the head and neck. Cancer 2000;88:876-883.

35. Forastiere AA, Goepfert H, Maor M, Pajak TF, Weber R, Morrison W, Glisson B, Trotti A, Ridge JA, Chao C, Peters G, Lee DJ, Leaf A, Ensley J, Cooper J. Concurrent chemotherapy and radiotherapy for organ preservation in advanced laryngeal cancer. N Engl J Med 2003;349:2091-2098.

36. Bachaud JM, Cohen-Jonathan E, Alzieu C, David JM, Serrano E, Daly-Schveitzer N. Combined postoperative radiotherapy and weekly cisplatin infusion for locally advanced head and neck carcinoma: final report of a randomized trial. Int $\mathrm{J}$ Radiat Oncol Biol Phys 1996;36:999-1004.

37. Bernier J, Domenge C, Ozsahin M, Matuszewska K, Lefebvre JL, Greiner RH, Giralt J, Maingon P, Rolland F, Bolla M, Cognetti F, Bourhis J, Kirkpatrick A, van Glabbeke M; European Organization for Research and Treatment of Cancer Trial 22931. Postoperative irradiation with or without concomitant chemotherapy for locally advanced head and neck cancer. N Engl J Med 2004;350:1945-1952. 
38. Cooper JS, Pajak TF, Forastiere AA, Jacobs J, Campbell BH, Saxman SB, Kish JA, Kim HE, Cmelak AJ, Rotman M, Machtay M, Ensley JF, Chao KS, Schultz CJ, Lee N, Fu KK;

Radiation Therapy Oncology Group 9501/Intergroup.

Postoperative concurrent radiotherapy and chemotherapy for high-risk squamous-cell carcinoma of the head and neck. N Engl J Med 2004;350:1937-1944.

39. Bonner JA, Harari PM, Giralt J, Azarnia N, Shin DM, Cohen RB, Jones CU, Sur R, Raben D, Jassem J, Ove R, Kies MS, Baselga J, Youssoufian H, Amellal N, Rowinsky EK, Ang

KK. Radiotherapy plus cetuximab for squamous-cell carcinoma of the head and neck. N Engl J Med 2006;354:567-578.

40. Siemann DW, Warrington KH, Horsman MR. Targeting tumor blood vessels: an adjuvant strategy for radiation therapy. Radiother Oncol 2000;57:5-12.

\section{Author Affiliations}

William M. Mendenhall, MD, Department of Radiation Oncology, University of Florida, College of Medicine, Gainesville, Florida

Russell W. Hinerman, MD, Department of Radiation Oncology, University of Florida, College of Medicine, Gainesville, Florida

Robert J. Amdur, MD, Department of Radiation Oncology, University of Florida, College of Medicine, Gainesville, Florida

Robert S. Malyapa, MD, PhD, Department of Radiation Oncology, University of Florida, College of Medicine, Gainesville, Florida

Christopher D. Lansford, MD, Department of Otolaryngology, University of Florida, College of Medicine, Gainesville, Florida

John W. Werning, MD, Department of Otolaryngology, University of Florida, College of Medicine, Gainesville, Florida

Douglas B. Villaret, MD, Department of Otolaryngology, University of Florida, College of Medicine, Gainesville, Florida 